\title{
Evolution of Microstructure and Precipitation State during Thermomechanical Processing of a Low Carbon Microalloyed Steel
}

\author{
P. Valles*, M. Gómez**, S. F. Medina**, A. Pastor*, O. Vilanova* \\ * Instituto Nacional de Técnica Aeroespacial (INTA),Torrejón de Ardoz, 28850 Madrid \\ ** C. N. Investigaciones Metalúrgicas (CENIM), Avda.Gregorio del Amo, 8, 28040 Madrid
}

The increasing demand of sources of energy such as oil and natural gas induces at the steel industry a development on low carbon microalloyed steels for pipeline applications in order to achieve excellent mechanical properties of strength and toughness at a reduced cost. To obtain an adequate fine-grained final structure, the strict control of thermomechanical processing and accelerated cooling is crucial [13]. Depending on the thermomechanical processing conditions and chemical composition, pipeline steels can present different microstructures. Several authors have found that the microstructure of acicular ferrite usually provides an optimum combination of mechanical properties $[4,5]$. Higher levels of austenite strengthening before cooling promote a refinement of final microstructure but can also restrict the fraction of low temperature transformation products such as acicular ferrite.

A series of anisothermal multipass hot torsion were carried out to simulate hot rolling on a low-carbon high-Mn (Nb, Ti)-microalloyed steel with increased hardenability obtained thanks to $\mathrm{Mo}, \mathrm{Ni}$ and $\mathrm{Cu}$ additions, designed for pipeline construction. Mean Flow Stress (Fig. 1) was graphically represented against the inverse of temperature to characterize the evolution of austenite microstructure during rolling. This combined effect gives rise to a wide range of final microstructures and mechanical properties depending on the composition, processing schedule and cooling rates applied. On the other hand, it is known that strain-induced precipitates formed by microalloying elements play a very important role on the microstructure evolution and final mechanical properties [5, 6, 7] Precipitation state at different stages of thermomechanical processing was studied on different samples obtained by means quench-interrupted hot rolling simulations.

The samples were studied by optical microscopy and scanning electron microscopy (SEM), after were prepared by metallographic techniques on a longitudinal surface (Figs. 2, 3). The primitive austenite grain boundaries were revealed by etching. The evolution of austenite microstructure during hot rolling simulation was obtained. The characteristics of the precipitates were determined by transmission electron microscopy (TEM), using the carbon extraction replica technique (Figs. 4, 5). In each replica a population of no less than 400 particles was counted and their size was measured with the aim of calculating the mean size. Energy dispersive X-ray (EDX) analysis was carried out to characterize the chemical composition of the particles observed. SAED patterns were also obtained. $(\mathrm{Ti}, \mathrm{Nb})$-rich carbonitrides can be found from reheating and their size keeps a constant value near 20$30 \mathrm{~nm}$ during thermomechanical processing. A second population of much finer (Nb,Mo)-rich precipitates whose size is close to $5 \mathrm{~nm}$ forms from lower temperatures.

References

1. T. Schambron, A. W. Phillips, D. M. O’Brien, J. Burg, E. V. Pereloma, C. C. Killmore, J.

A.Williams, ISIJ Int. 49: 284-292, 2009

2. M.-C. Zhao, K. Yang, Y.-Y. Shan, Mater. Lett. 57: 1496-1500, 2003

3. C. I. Garcia, K. Cho, M. Hua, A. J. DeArdo, Mater. Sci. Forum 638-642: 124-129, 2010.

4. M.-C. Zhao, K. Yang, Y.-Y. Shan, Mater. Lett. 57: 1496-1500, 2003

5. Y. M. Kim, H. Lee, N. J. Kim, Mater. Sci. Eng. A 478: 361-370, 2008

6. M. Gómez, S. F. Medina, P. Valles, ISIJ Int. 45: 1711-1720, 2005

7. S. Shanmugam, N. K. Ramisetti, R. D. K. Misra, J. Hartmann, S.G. Jansto, Mater. Sci. Eng. A478: 26-37, 2008 


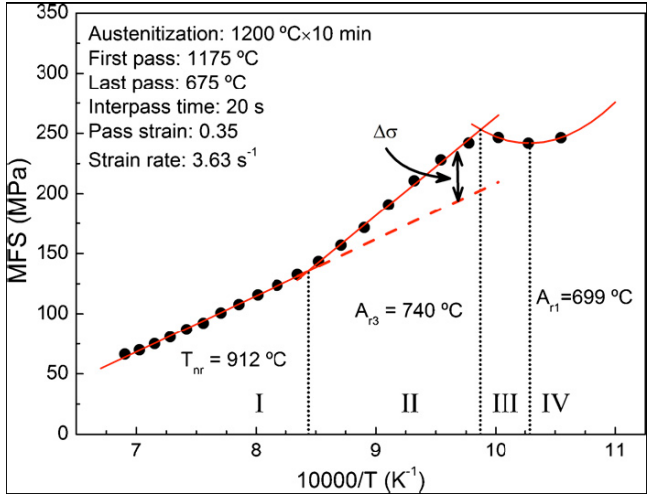

Figure 1. Mean Flow Stress (MFS) versus the inverse of absolute temperature according to a hot rolling simulation schedule using average values for strain, strain rate and interpass time.
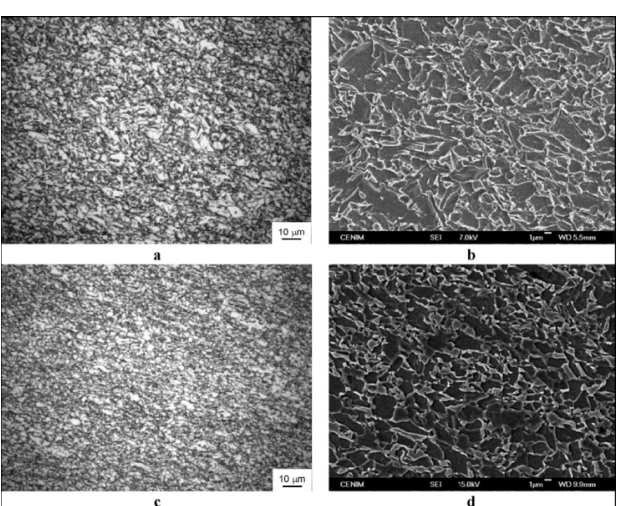

Figure 2. Microstructure at the end of hot rolling simulation observed by optical microscopy (left) and SEM (right).

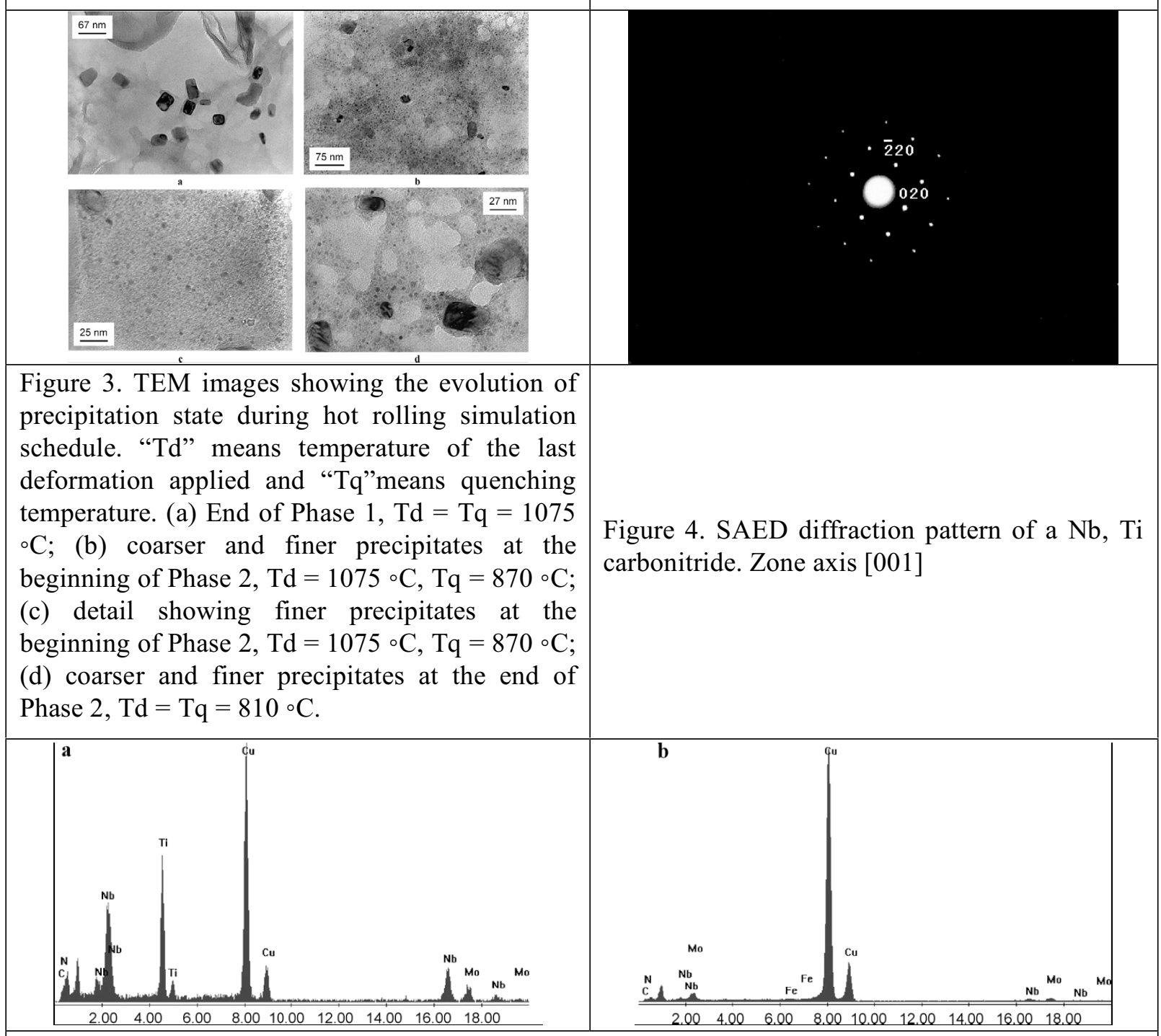

Figure 5. EDX analysis spectra of precipitates found at $810{ }^{\circ} \mathrm{C}$, i.e. the end of Phase 2. (a) Coarser particle with $\mathrm{Ti}, \mathrm{Nb}$ and $\mathrm{Mo}$; (b) finer and more globular particle with $\mathrm{Nb}-\mathrm{Mo}$. 